\title{
Siete puertas para abrirnos a otro Trabajo Social
}

\author{
Seven Doors to Open Us Up to Another Social Work \\ Miren Koldobike Velasco VÁzQueZ \\ Red Canaria en defensa del sistema público de Servicios Sociales \\ koldobivelasco@gmail.com
}

Recibido: 30/10/2011

Revisado: 03/11/2011

Aceptado: 22/11/2011

Disponible on line: 03/08/12

\begin{abstract}
Resumen
En el presente artículo pretendemos comunicar algunas claves para sacarnos de un dominante Trabajo Social mecanicista y tecnocrático y retomar nuestro papel ético en la defensa de los derechos, de nuestra tarea de acompañar procesos de empoderamiento, de visibilizar el dolor, de hacer alianza con las personas con las que compartimos procesos de transformación, etc., a través de la apertura a siete puertas: Mirar y transformar nuestras miradas; imaginar que podemos; reinventar la voz; crear conciencia y construcción colectiva; la acción reivindicativa es Trabajo Social. Recortes sí, pero para la acumulación del capital y una experiencia de reivindicación en red.
\end{abstract}

Palabras clave: compromiso, reivindicación, política, reflexión, organización.

\begin{abstract}
In this article we seek to communicate some keys to remove ourselves from a dominant mechanistic and technocratic Social Work and to take back our ethical role in defending rights, in our task of managing the processes of empowerment, in making pain visible, in building alliances with the people with whom we share transformation processes, etc., by opening seven doors: To see and transform our views, to imagine that we can to reinvent our voice, to create awareness and collective action, to engage in protest is Social Work. Scraps, yes, but in order to accumulate capital and for experience in a network of protest.
\end{abstract}

Key words:commitment, protest, policy, reflection, organization.

Referencia normalizada: Velasco Vázquez, M. K. (2012): «Siete puertas para abrirnos a otro Trabajo Social». Cuadernos de Trabajo Social, 25(2): 471-476.

Sumario: Introducción. 1. Puerta $1^{\mathrm{a}}$ : mirar y transformar nuestras miradas. 2. Puerta $2^{\mathrm{a}}$ : imaginar que podemos... 3. Puerta $3^{\text {a }}$ : una reinvención de la voz. Somos voz, somos altavoz... sin robar poder desde el Trabajo Social. 4. Puerta $4^{\mathrm{a}}$ : conciencia y construcción colectiva. «Hemos pasado del miedo a arreglar papeles a salir en la televisión». 5. Puerta $5^{\text {a: }}$ la acción reivindicativa es Trabajo Social. 6. Puerta $6^{\text {a }}$ : recortes sí, pero para la acumulación del capital. 7. Puerta $7^{\text {a }}$ : «la unión del rebaño obliga al tigre a dormir sin cenar». Una experiencia por los Servicios Sociales en red. 8. Referencias bibliográficas.

\section{Introducción}

No existen ideas nuevas, tan sólo nuevas formas de conceder poder y espacio en nuestras vidas a las ideas que apreciamos (Audre Lorde)

$\mathrm{Y}$ es verdad. Si buscas nuevas ideas éste no es el ensayo, pero si buscas compartir ánimos para hacerle hueco en nuestra vida a algunos de los planteamientos que apreciamos, puede ser un buen comienzo.
El intento es claro: hacernos salir de un dominante Trabajo Social mecanicista y tecnocrático y retomar nuestro papel ético en defensa de los derechos, de nuestra tarea de acompañar los procesos de empoderamiento, de visibilizar el dolor, de hacer alianza con las personas con las que compartimos procesos de transformación...

Casi con más humildad que timidez, les invito a entrar en las siete puertas que nos pueden entusiasmar a esta recuperación de nuestro Trabajo Social en clave de re: recordando el 
sentido, retomando objetivos, reconceptualizando, revisando miradas, reflexionando, reanimando, respirando, repolitizando..., inspiradas por la gente de cada día y sacando para fuera nuestros miedos que a la luz se hacen chiquitos.

\section{Puerta $1^{\text {a }}$ : mirar y transformar nuestras miradas}

Hoy es esencial mirar nuestra mirada, despojarla de esquemas prefijados, de tablillas de observación que conviertan todo lo humano en medible y pesable, salirnos de una mirada que concibe el mundo en línea y pasar a aprender a ver la realidad como realidades, con su diversidad y su riqueza, con perspectiva de complejidad, comprensión...

Superar la mirada del modelo vertical que busca las causas conductuales de la injusticia y la desigualdad y se centra en los cambios individuales cuyo propósito es persuadir; que apuesta, siguiendo al maestro Freire (1975), por una pasiva educación bancaria, considerando a las personas como receptoras pasivas, usuarias de servicios y objetos de cambio. Es necesario pasar a mirar en horizontal, y con una perspectiva estructural, buscar las voces de la pobreza, en igualdad y con conciencia crítica, teniendo como objetivo el cambio social a través de la participación activa, libre, analítica, dialógica y debatible.

Dejar de ver en la superficie y adentrarnos en el pozo, hasta lo oscuro, y ver siendo. Nuevas gafas que nos permitan ver el fondo y con ello se haga posible que nuestras manos estén en activo, removiendo más las raíces y menos las ramas.

\section{Puerta $2^{\mathrm{a}}$ : imaginar que podemos...}

Todas las cosas son imposibles mientras lo parecen (Concepción Arenal)

Lo que activa e impulsa la energía transformadora fue y es la capacidad de imaginar una posibilidad de cambio. En la actualidad, estamos paralizadas con el conformismo del fatalismo, del no se puede hacer nada, del reino de la impotencia y la desconfianza... Nos hace falta un salto de esta actitud en Trabajo Social. Andamos programadas y autocensuradas, cerrándonos a lo «inédito viable», que exponía Freire.
Hay que pasar de «la imaginación contra el poder», al poder de la imaginación y la necesidad de apropiarnos de la potencia. Transformar nuestras debilidades en potencialidades y no hacer recuentos de carencias, que acaban victimizándonos y congelando las posibilidades de transformación. Imaginar y utopizar que sí, otro mundo es posible, manos a la obra para vivirlo y hacerlo llegar. Despertar de este mal sueño que nos aborrega y aliena, en el que vamos poniendo censuras a nuestros cambios, antes de intentarlos.

Para poder estar tenemos una tarea arqueológica de desenterrar los derechos, de luchar por el derecho a tener derechos, como decía Hannah Arendt. Para participar hay que estar en los escenarios vetados a las personas y colectivos apartados del poder, la riqueza, la propiedad... Y reinventar tablados de realidad cotidiana en los que nuestra riqueza sea el nivel de cuidados que nos dispensamos unas personas a otras... porque «somos lo que amamos».

Y si nos salimos de la queja, se nos abren ventanas de luz que con rigor y tesón nos llevan a hacer posible lo que soñamos e imaginamos. Y por cierto habrá que re-hacer sueños y utopías que andan con anemias de posibilismo de siglos de un no, para las mismas personas, en estado de guerra permanente.

Necesitamos un Trabajo Social que recupere la capacidad de concebir mundos alternativos, múltiples, libres, igualitarios, diversos...; ya que «sólo esta capacidad que nos otorga la utopía permite al ser humano traducir su primaria reacción negativa en una divergencia constructiva, que nos mueve a diseñar un plan alternativo a la realidad (Krotz, 1998).

\section{Puerta $3^{\mathrm{a}}$ : una reinvención de la voz .So- mos voz, somos altavoz... sin robar poder desde el Trabajo Social}

Creíamos, creemos, que para no ser mudo hay que empezar por no ser sordo, y que el punto de partida de una cultura solidaria está en las bocas de quienes hacen cultura sin saber que la hacen, anónimos conquistadores de los soles que las noches esconden, y ellos, y ellas, son también quienes hacen historia sin saber que la 
hacen. Porque la cultura, cuando es verdadera, crece desde el pie, como alguna vez cantó Alfredo Zitarrosa, y desde el pie crece la historia. Lo único que se hace desde arriba son los pozos

(Eduardo Galeano)

El concepto de participación que integra el proyecto neoliberal es indicativo de sus principios generales. La participación se define instrumentalmente en función de las necesidades generadas por los ajustes estructurales requeridos, específicamente las asociadas a la reducción del Estado mediante el traspaso de las responsabilidades sociales a la sociedad civil $\mathrm{y}$ al sector privado. El principio básico parece ser la adopción de una perspectiva privatizadora e individualista, capaz de reemplazar y redefinir la noción colectiva de participación social.

Las concepciones de ciudadanía, sociedad civil y participación formuladas por el proyecto neoliberal expresan una intención des-politizadora y una visión minimalista de la política. Es necesario pasar de la democracia representativa, a la participativa y de ella a la democracia en desarrollo, que se centra en «el trabajo de fortalecer las capacidades de acción colectiva auto-dirigida, para resolver problemas y crear bienes individuales y comunes, por encima de las diferencias. Pasar del poder sobre, al poder con y al poder a (...)» (Biekart y Fowler, 2011).

Como expone Marta Gutiérrez (2005): «mientras los pilares de la democracia son participación, transparencia e intercambio del conocimiento y de poder con las demás personas, la cultura institucional parece estar sólidamente asentada sobre tres pilares: el papeleo burocrático, el secreto y el reparto del poder». La dinámica del poder de la tecnocracia está disfrazada por el hecho de que los expertos dominantes están llenos de intenciones igualitarias e inclusivas de ayudar. Es un enfoque del rescate, no de acción conjunta, las profesionales cargan con toda la responsabilidad, las personas usuarias no son co-productoras. Se necesita acción que deje espacio para la participación de las personas. La auto-organización de la ciudadanía para participar en el proceso de toma de decisiones es fundamental, porque la ciudadanía somos sujetos de cambio y no sólo objetos para poner a prueba políticas económicas y sociales.

Desde el Trabajo Social, muchas veces intervenimos, interferimos, obstaculizamos y ahogamos diversos procesos sociales generados por los grupos sociales en los que trabajamos. Esta categoría, en palabras de Elí Evangelista (2011): «debería de ser transformada hacia los marcos conceptuales de la potenciación social, donde se involucra la posibilidad de facilitar la capacidad creadora, organizativa y asociativa de los actores sociales»».

Un reto enorme de nuestro tiempo es desarrollar una política de «agencia transformadora», como alternativa a la política tecnocrática, en la que las personas no son apoderadas por líderes sino que se empoderan por sí mismas al desarrollar habilidades y hábitos de acción cooperativa y al cambiar las instituciones y los sistemas para que sirvan de mayor soporte a la acción de cambio.

En todo ello, el papel que las personas trabajadoras sociales tenemos es de:

Acompañante, promotora y facilitadora, que se inserta en la misma realidad que actúa, que coexiste e interacciona con sus integrantes y que incide en potenciar habilidades, capacidades y destrezas colectivas, construyendo relaciones horizontales, dialógicas y autogestionadas, construyendo espacios de poder alternativos (Gutiérrez Sastre, 2005).

En cualquier caso redefinir nuestro papel de ser voz de los sin voz, que puede ser una manera sutil de quitar la voz. Potenciando una «re-imaginación de la voz», que facilite compartir voces, ser altavoces, rehacer la voz de las personas y colectivos silenciados, sin restas, con sumas y melodías corales nuevas. La transformación es crear oportunidades para que toda la ciudadanía aporte sus talentos, experiencia y habilidades al proceso de desarrollar nuestro mundo. Es crear colectivamente espacios de encuentro y diálogo necesarios para el desencadenamiento de participación organizada y con conciencia crítica, la que protesta y propone. Estando con lo que expresa Mamphela Ramphele (2008): «El desarrollo no se le puede hacer a las personas. Las personas se deben de convertir en agentes de su propio desarrollo». 
4. Puerta $4^{\mathrm{a}}$ : conciencia y construcción colectiva. «Hemos pasado del miedo a arreglar papeles a salir en la televisión»

Es importante tener siempre claro que inculcar en los dominados la responsabilidad de su situación forma parte del poder ideológico dominante. De allí la culpa que ellos sienten, en determinado momento de sus relaciones con su contexto y con las clases

dominantes, por encontrarse en esta o aquella situación de desventaja... Muchas personas empobrecidas forman parte de las legiones de ofendidos que no ubican la razón de ser de su dolor en la perversidad del sistema social, económico, político en que viven, sino en su propia incompetencia. Mientras se sientan así, piensen así y actúen así, reforzarán el poder del sistema. Se vuelven conniventes con el orden deshumanizante».

(Paulo Freire, Pedagogía de la autonomía)

El Trabajo Social crítico sostiene que las personas no son ni parcial ni totalmente culpables de las circunstancias personales y sociales a las que se enfrentan, sino que apuntan como causantes de dicha situación opresiva a los orígenes sociales y a las estructuras sociales. Para ello, la concienciación es una estrategia clave para la transformación. Un proceso de reflexión en el que la persona oprimida comprende que su problema no es achacable únicamente a sí misma, sino que está arraigado en la estructura social. También cae en la cuenta de que la experiencia vivida está directamente relacionada con su pertenencia a un grupo oprimido.

Otra estrategia importante es la «identificación colectiva». Se basa en la idea de concienciarnos colectivamente, como condición previa para iniciar acciones comunes dirigidas por las mismas personas que las sufren. Nuestro papel en este punto es el de facilitar las condiciones y capacidades para apoyar estos procesos, como decía Freire: «perseguir la toma de conciencia de su situación de opresión y ayudarles a perder el miedo y luchar por su libertad y dignidad». No se trata obviamente de obligar a la población explotada y sufrida a que se rebele, que se movilice, que se organice para defenderse, valga decir, para transformar el mundo - como dice P. Freire - lo vital es desarrollar, junto al trabajo específico de cada uno de nuestros campos:

Desafiar a los grupos populares para que perciban, en términos críticos, la violencia y la profunda injusticia que caracteriza su situación concreta. Aún más, que su situación concreta no es destino cierto o voluntad de Dios, algo que no puede ser transformado.

Todo lo contrario, es realizado por el ser humano y por tanto mutable. Con todo, nuestra tarea y finalidad como trabajadoras sociales consiste en apoyar la construcción de sujetos sociales, lo que implica generar procesos de organización y participación, que en sí sean espacios y referentes de ejercicios y aprendizaje de ciudadanía, con claridad sobre nuestros derechos y mecanismos para hacerlos cumplir. Lugares donde «no sobra nadie».

\section{Puerta $5^{\mathrm{a}}$ : la acción reivindicativa es Tra- bajo Social}

El Trabajo social tiene una doble y paradójica referencia: por un lado, la asistencia frente al sufrimiento social, y por otro, los ideales democráticos de promoción, de auto-organización y de emancipación de las personas»

(Cristina de Robertis. Fundamentos del Trabajo social)

Cuando releemos el objetivo, la definición, los principios y nuestro Código deontológico en Trabajo Social no cabe duda de que nuestra tarea tiene una dimensión política, de preocupación por el bien común, de promoción de derechos y de reivindicación. Eso sí, compuesta de protesta, para neutralizar el poder dominante y de propuesta, para construir poder. La cuestión es clara, nos hemos convertido en huérfanas de esta tarea, que nos pone entre nuestras dedicaciones el sacar los conflictos a la luz. Preferimos separarnos de esta dimensión para seguir engrasando la barbarie, al bajo coste de seguir cobrando una nómina. La pregunta clave es con quiénes tenemos la alianza y nuestro compromiso, según lo que respondamos evitaremos nombrar ciertas cosas y dejaremos nuestras funciones de denuncia hibernando. Podemos abrir esta puerta, junto con otras gentes, que puedan ser cómplices de sacar a la visibi- 
lidad aquello que se oculta y de lo que somos testigos, en el Trabajo Social, día tras día. Esta tarea es nuestra y si la dejamos de hacer, dejamos de ser toda la profesión.

\section{Puerta $6^{\mathrm{a}}$ : recortes sí, pero para la acu- mulación del capital}

Dice el cachorro: "No hay nadie como yo», orgulloso de su primera caza. Pero la jungla es grande y él es pequeño.

(Ruyard Kipling, Consejos de Baloo a Mowly. El libro de la selva)

Claro que hay que recortar, pero sobre todo entre otras partidas, las del gasto militar que en dos días se lleva lo que se dedica a financiar el Plan Concertado para todas las comunidades autónomas. Con lo que el Estado invirtió en militarismo, 1 de cada 10 euros, en el 2011, se podrían haber mantenido 421.910 pensiones mínimas al año. Hay que recortar ¿cómo no? en dedicación a mega proyectos que confunden «lo grande, con lo grandote», como dice Galeano, invirtiendo en faraónicas infraestructuras que sólo contribuyen al enriquecimiento de la gente de siempre..

Recortar mecanismos de acumulación de capital, a través del control de la contribución fiscal, persiguiendo el fraude fiscal, invadiendo paraísos fiscales, no permitiendo la concentración de propiedades en pocas manos y ejerciendo el derecho a redistribuir rentas, propiedades, poder y los cuidados. Eso sí, ni un recorte sobre los servicios públicos y menos aún sobre los pilares del Estado de Bienestar. Y si no amenazamos con convertir los Servicios Sociales en bancos para que nos rescaten.

Recuperar un Trabajo Social que promueva la justicia redistributiva, equitativa y social; releyendo y practicando nuestra definición internacional:

La profesión de trabajo social promueve el cambio social, la resolución de problemas en las relaciones humanas y el fortalecimiento y la liberación del pueblo para incrementar el bienestar. Mediante la utilización de teorías sobre comportamiento humano y los sistemas sociales, el trabajo social interviene en los puntos en los que las personas interactúan con su entorno. Los principios de los Derechos Humanos y la Justicia Social son fundamentales para el trabajo social (FITS, 2000).

\section{Puerta $7^{\mathrm{a}}$ : «la unión del rebaño obliga al tigre a dormir sin cenar». Una experiencia por los Servicios Sociales en red}

En noviembre de 2010 convocamos, desde el Colegio de Trabajo social de Las Palmas, una reunión para tomar el pulso de la situación de los Servicios Sociales, los recortes que se anunciaban y las consecuencias que los mismos iban a tener sobre la gente más empobrecida. A partir de este encuentro decidimos organizar una Red Canaria en Defensa del sistema público de Servicios Sociales, espacio del que nos hemos dotado, con diversas funciones:

- Estudio de la realidad social, los Servicios Sociales, sobre los recortes, de los presupuestos, del incumplimiento de los derechos sociales...

- Comunicación de todas las situaciones ocultadas e invisibilizadas. A través de charlas, participación en mesas redondas, ruedas y notas de prensa, atención a los medios de comunicación, realización de un blog: http://blogredess.blogspot.com/, información de noticias por correo electrónico(redesscan@gmail.com)...

- Movilización, recuperando la calle, participando con nuestras ideas en protestas de otros colectivos y realizando teatro de calle, para hacer llegar el mensaje de manera original y fresca.

- Alianzas. Este es un aspecto central de la red, nos estamos coordinando con otras organizaciones en defensa de la educación y de la salud, participamos de la alianza estatal por los servicios sociales, somos parte de «Democracia en movimiento»... estamos atentas a cualquier posibilidad de hacer sinergia y unidad en las luchas.

- Organización. Sin lo cual no mantendríamos nada: mensualmente nos reunimos representantes de diferentes colectivos que adhieren a la red para articular internamente cada nudo y el trabajo de cada equipo de acción.

Hemos elaborado dos manifiestos, con los que hemos recogimos más de 5.000 firmas personales y casi 70 adhesiones colectivas. $\mathrm{Pa}-$ ralelamente vamos apoyando el proceso de auto-organización de las personas afectadas por los recortes en Servicios Sociales en algunos barrios de la ciudad de Las Palmas de Gran Canaria. Creamos un manifiesto titulado Los servicios sociales son un derecho y además de recoger apoyos, lo presentamos en la sede del 
Gobierno de Canarias. Hasta hoy sigue un grupo de personas afectadas reuniéndose y participan en la red, como un colectivo más. Hemos ido creciendo en nudos, hay actualmente funcionando la red en tres islas y con articulación: Gran Canaria, Tenerife y Fuerteventura.

Muchas han sido las dificultades con las que nos hemos ido encontrando: miedo a informar, a organizarse, a expresar opiniones, a exigir derechos; escasa dedicación de tiempo, recursos y compromiso a la incidencia política y movilizaciones; cuesta de-construir el discurso dominante; invisibilización de la realidad de desigualdad y de los servicios sociales.; escasa estabilidad en la participación; bloqueos para introducir los servicios sociales en agenda política y pública; poca cultura de investigación en lo social; implicación insuficiente de las organizaciones sociales-políticas con este tema; opacidad a la hora de facilitar datos, dependencia institucional de algunas de las entidades al estar pendiente de convocatorias de subvenciones, y convenios de colaboración; gran diversidad, variedad y complejidad de estructuras, servicios, programas que existen en los municipios, dificultan su tratamiento estadístico; los medios humanos y materiales limitados... y es que trabajamos con pico y pala...

Con estos y otros obstáculos lo más importante de esta experiencia van siendo los aprendizajes y esperanzas que vamos desarrollando: la importancia de poner en el centro el debate de lo público, la universalidad, la responsabilidad pública, el reparto de la riqueza, los derechos sociales.

Es clave visibilizar y acompañar el dolor, el sufrimiento y generar procesos de concienciación y empoderamiento. Rescatar la cultura de la reivindicación y los derechos. Crear redes de apoyo mutuo y romper el aislamiento. Es necesario partir de diagnósticos serios sobre la si- tuación de los Servicios Sociales y la inversión social en el Estado español. Partir de la creencia en lo que estamos haciendo, no olvidando las causas y buscar modelos alternativos al sistema capitalista. Hacer visible la necesidad y la existencia de una red de Servicios Sociales públicos. Crear canales de comunicación y colaboración con colectivos, entidades, asociaciones, profesionales, particulares. Potenciar herramientas de información, difusión y reivindicación. Redescubrir la importancia de las alianzas para la incidencia política. Con el convencimiento de la influencia transformadora desde lo pequeño y la importancia de la comunicación y popularización de los mensajes, para conectar con las mayorías que acumulan «las desventajas». Y ahí seguimos, creciendo, reivindicando y siendo ya parte del paisaje... porque es posible y lo estamos viviendo ya.

Siete puertas para el Trabajo Social para que como bellísimamente decía Walt Whitman:

No dejes que termine el día sin haber crecido un poco, sin haber sido feliz, sin haber aumentado tus sueños.

No te dejes vencer por el desaliento. No permitas que nadie te quite el derecho a expresarte, que es casi un deber.

No abandones las ansias de hacer de tu vida algo extraordinario.

No dejes de creer que las palabras y las poesías

sí pueden cambiar el mundo. ....No permitas que la vida te pase a ti sin que la vivas...

En África, Saamspan, significa «Pongámonos a trabajar», pues ahí nos encontraremos, abriendo puertas...

\section{Referencias bibliográficas}

Biekart, K. y Fowler, A. (2011). El cambio dirigido por la acción cívica. El poder de la imaginación ciudadana. Barcelona: Icaria.

Evangelista Martínez, E. (2011). Aproximaciones al Trabajo social contemporáneo. México: Editorial Red de investigaciones y estudios avanzados en Trabajo social.

Freire, P. (1975).La educación como práctica de la libertad. Madrid: Siglo XXI.

Gutiérrez Sastre, M. (2005). La participación en los servicios públicos de bienestar: un análisis del poder de los usuarios en el ámbito de la salud, la educación y los servicios sociales. Madrid: Consejo Económico y Social de España.

Krotz, E.(1998). Utopía. Saltillo México D.F.: Universidad Autónoma de Coahuila. 